\title{
Exploring 21st Century Collaboration Through a Curricular Lens at the University of Wisconsin La Crosse
}

\author{
Joshua Miller \\ University of Wisconsin La Crosse \\ United States
}

\begin{abstract}
The art of teaching and learning within the globalized 21 st century inherently challenges the traditional instructional process, as students seek greater opportunities that facilitate a deeper emphasis on communication, collaboration, and cooperation. Further, as preexisting boundaries are easily circumnavigated through the immediacy associated with smart devices it is advisable that educators prepare individuals who are capable and experienced in developing meaningful relationships where information is freely exchanged across these former borders. Through a conceptual analysis of viewing global collaboration through a curricular lens, this brief article explores a pedagogical perspective that considers the call for a greater emphasis on living and learning in a global community. Such endeavors, especially involving teacher preparation programs, serve to foster culturally and globally responsive citizens who view global collaboration through a curricular and pedagogical lens.
\end{abstract}

\section{Introduction}

Fink [1] extends a discussion, which challenges the ubiquitous use of traditional pedagogical approaches across college campuses today as well as the skills learned through such instruction. His position is to refocus the concept of teaching and learning as an evolving endeavor that recognizes the individual, institutional, and societal need for increasing academic success and college degree attainment. The fact is, systemically speaking, we yearn to increase both access to and success in college; yet, we are only now repositioning the conversation to question what is being taught within higher education. In an everincreasing globalized world, we now recognize the need to foster cultural and global competencies in our graduates, through intentional teaching practices that emphasize the development of such soft skills as cooperation, communication, and collaboration. Ultimately, those of us in higher education have warmed to the idea that if our students are to learn deeply, they must do so through creative pedagogical activities that establish collaborative learning that moves beyond the classroom and into the local, national, and international communities.

Wenger [2] describes education as a process that while formative has the capacity to transform learners by moving the discussion beyond the learned attribute of knowledge and into a world of endless application possibilities. Similarly, Bruner [3] emphasizes an approach to understanding the applicability of knowledge, which provides the student with flexibility that is not limited by a simple outcome. Over his course of influence, which continues today, Bruner [4] refined his vision of teaching and learning to incorporate the communicative nature of the educational process ascribing a relational aspect. In this it is clear that the onus of education is not a simple transfer of content knowledge; rather, as Buchner [5] attributed to the thinking of Kant, it is the self-activity where students are taught how to think and how to learn. In response to living and learning in a globalized society, it behooves educators to incorporate international partnerships and collaborations that serve to enrich the educational experience.

Barkely et al. [6] advance collaborative learning as an endeavor that involves knowledge construction through a socially constructed environment. This environment is where the student drives the learning endeavor through personal relevance and a structured approach to addressing real-world problems. The advantages of this approach, within the field of teacher preparation, include the development of selfauthorship, an increased exposure to diverse perspectives, and both personal and professional experience working with expanding partnerships. When considered from a globalized educational perspective, it is possible to view the true strengths of collaboration through what Joseph [7] terms as a curricular lens that values cultural literacies and challenges conventional approaches to pedagogy.

It is Kumaravadivelu [8] who advances the descriptive role of $21^{\text {st }}$ century teachers as being both "mediators and negotiators" (p. 317) where the teacher 
navigates the educational milieu from in a global perspective. With a nod to $21^{\text {st }}$ century technologies, and an appreciation that the world is rapidly shrinking, a significant aspect of teacher preparation programs must now include a broadening and deepening of the cultural literacies of necessary for future educators. A curriculum lens that emphasizes global partnerships and collaboration would inherently incorporate the appreciation for human differences.

\section{Current initiatives UWL DES}

Currently within the Department of Educational Studies at the University of Wisconsin-La Crosse, the overarching desire continues to focus on fostering collaborative learning opportunities that allow education majors to become immersed in real world projects. For example, in courses that embrace aspects of education within a globalized society, teacher candidates often connect with students, faculty, and staff from across the globe where they engage in critical conversations involving access, equity, and equality of education. Further, students have recently been provided with the opportunity to spend a month living, teaching, and learning throughout China. Similarly, students who engage in coursework involving multicultural education are provided with opportunities to engage in summer seminars in areas such as Milwaukee, which is the largest and most diverse city in Wisconsin. The concept is that these projects will allow students to see beyond the literature, and experience the globalized, diversified world from a personal perspective.

These collaborative relationships are better defined as partnerships, as the underlying hope is to cultivate an exchange of mutually beneficial ideas and resources, which align with Zhao's [9] perspective that such endeavors must become sustainable. From a local standpoint, students engaged in taking educational foundation courses, generally associated with first and second year students, spend nearly 20 hours per semester in the neighborhoods of our local community. The primary purpose for this level of community involvement is to foster a deeper understanding of the social determinants of education, which by in large influence the access and quality of instruction. Through applied experiences, my students are invited into the daily lives of the families they will serve as educators, and thus begin cultivating the cultural literacies necessary for meaningful instruction. Potential future collaborations include having our students work with the County Health and Human Services Department, where students will spend time embedded within the community side-byside with multiple community stakeholders. These would include caseworkers, family medical residents associated with Gundersen Health, and youth services experts such as the YMCA, as a means of enriching individual appreciation for the diversity of families and students within the local community.

On a national level, I continue to seek opportunities to connect students with virtual collaborative prospects between education majors enrolled at other institutions. Specifically, the thought is to connect future educators from across regions within the United States in an effort to address legitimate concerns involving what Welner [10] refers to as the increasing gaps in both opportunity and achievement. The hope is that our students will share experiences related to access, equity, and equality of education in an attempt to develop strength-based lessons for meeting the diverse needs of all students (local and national). It is routine for our education majors to form professional learning community (PLC) teams within each course, as described by DuFour, Eaker, and Karhanek [11]. Ideally, these teacher candidates connect with teacher candidates from other institutions, as a means of synthesizing ideas from across diverse perspectives. These collaborations would then yield multimodal curriculum projects that address the social determinants of education through innovative lesson planning and service learning projects.

From an international perspective and after more than a year of research, planning, and logistical analysis, the University of Wisconsin-La Crosse launched a faculty-led study abroad program to China in May 2017. This program was conceptualized by Assistant Professor of Educational Studies Joshua Miller and developed in conjunction with the Dr. Ryan McKelley from the Department of Psychology. This immersive learning opportunity provided 14 education majors the chance to live, learn, and teach in China while wrestling with foundational issues of pedagogy and praxis. Without the sustainable partnership, as advocated by Zhao [9] between the University of Wisconsin-La Crosse and Foreign Language School \#2, located in Luoyang, China this opportunity would not have been possible.

Students enrolled in on-campus courses such as Education within a Global Society, are routinely presented with the opportunity to collaborate with students and scholars from across the globe including educators from the La Crosse sister city of Louyang, China. Having dedicated two weeks of traveling throughout China in September 2016 with the UWL Provost as well as the UWL Dean of the School of Education, we successfully identified and secured institutional partnerships with multiple primary, secondary, and post secondary schools. Our aggressive academically based travels yielded an approved faculty-led-study-abroad program, where 
one faculty member from the Department of Psychology and one faculty member from the Department of Educational Studies guided 14 UWL education majors throughout China during the months of May and June 2017. During this study abroad program, students worked alongside teachers, students, and scholars from China on such topics as curriculum, pedagogy, and scholarship, which transformed the educational perspectives of program participants [2].

This premiere study abroad program was designed to offer UW-L students, emphasizing the experiences of teacher candidates, the opportunity to earn six (6)credits by mingling learning experiences that extend between Lifespan Development (Psychology 212) and Education in a Global Society (Educational Studies 309) /w a cultural lab (Education Studies 475). These academic experiences were enhanced through in-depth cross-cultural collaborations with Chinese institutions of learning to include: Foreign Language School \#2 in Luoyang, China. Our students were given the time and space to explore human development and education as they wrestled with both eastern and western perspectives via their lived experiences within the US and China. Experiencing Chinese culture, via a study aboard program, is unlike many other international academic opportunities in that it is comprised of a myriad of cultural distinctions based upon a 5000-year history that evokes a global mindset, which served to increase the cultural literacies of our students [12].

China is truly a sea of peoples, both foreign and domestic, living, learning, and sharing within a confined space where each day offers a new opportunity for personal discovery. It is a world of modern marvels in the form of technologies and advancements; yet, it also remains true to ancient traditions, values, and customs. This program provided students with a deeper understanding of the social forces that shape education within a global society, as they opened themselves to new experiences never before imagined. As we examined such topics as comparative and international education, globalization, as well as the historical, theoretical, and methodological approaches of human development, our students found themselves immersed in a world where each day fostered useful skills that will serve the student for the rest of her or his life.

Additionally, in relation to the one (1) credit Cultural Lab, students experienced a deeper sense of immersive learning, as they lived with multiple host families in Luoyang, China. Foreign Language School \#2 is renowned for its ability to offer international students host families who are able to introduce local culture, while providing a safe and relatively familiar living environment. UWL students each had her / his private room with access to daily showers (in Western Tradition), but otherwise experienced life as an extended member of the family sharing meals, conversation, running errands, and preparing for class. The school takes pride of ensuring that each host family is purposefully recruited and screened by school administration to offer above average accommodations in a smoke-free environment. Host families provided transportation to and from school, as well as offer additional activities that served to enrich the overall student experience.

Finally, it is the hope of the Department of Educational Studies to encourage UWL education majors to consider working with institutions of higher learning throughout the globalized world. It has been my desire to have students work with peer education majors who are dedicating their lives to wrestling with the concepts of equity and equality, specifically with programs like the Institute for Social Justice and Reconciliation at the University of the Free State in South Africa. These burgeoning partnerships, which according to Zhao [9] are more robust than one-time collaborations, possess the potential to yield amazing opportunities for immersive learning projects. Such projects would serve to explore the elements of developing globally responsive educators with increased cultural intelligence and competencies as indicated by Ang and Dyne [12].

By offering UWL students the opportunity to experience the globalized world through local, national, and international partnerships, they will be challenged to think of their positionality in our everchanging world. Moreover, by using these local, national, and global collaborations as a curricular lens, our students will explore what Joseph [7] speaks to as an "in-depth examination of practice, interactions, values, and visions" (p.3). Future educators will be presented with direct opportunities to explore educational issues through the lived experiences of students, teachers, and scholars from across the globe, and partner to pursue solutions to questions of access, equity, and equality. These philosophically based pursuits will serve to ignite the intrinsic, autonomy yielding motivation to engage more deeply as globally responsive educators.

Another high impact learning activity that challenges the traditional approaches to teaching discussed by Fink [1] that I incorporate into my classroom is a multidimensional and multi-modal debate project. Throughout this semester-long collaborative project, students cooperatively designed a multimodal debate project using a strong studentcentered approach. The project allows students to: 12 identify a topic of personal interest, 2) conduct a literature review, 3) conduct research via classroom interviews and or surveys, and 4) construct a policy- 
position paper in support of their final stance on the educational issue under exploration. The overall onus of this project is to support collaboration and communication, as everything from the project topic to the final position paper will inherently involve negotiation and consensus.

The manner in which you construct your final project is $100 \%$ up to the discretion of your group. There is no correct approach; rather, your creativity is of the utmost importance. Simply be sure to meet the standards defined in this description.

\section{Body of knowledge}

High impact practices, such as collaborative and cooperative learning, as well as study abroad opportunities, are directly connected to both student engagement and academic attainment [12]. These practices are designed to foster a reciprocation of effort from students who desire to remain engaged within the learning community. While access to and enrollment in higher education continue to rise in the United States, rates of college persistence and degree attainment continue to remain an area of increased concern. Student attrition in the United States has now topped $50 \%$ of enrollment, with $67 \%$ of those dropping out within the first three semesters of matriculation [13]. Complicating the problem is the realization that nearly $25 \%$ of all university students drop out of traditional four-year institutions, between their second and third academic terms, with over $50 \%$ doing so at the two-year institutional level [13].

Kuh [14] emphasizes the need to introduce high impact practices that will intrusively incorporate students into the learning community. This process prepares students for life beyond the academic setting. According to Morse [15] failing to prepare every student so that they are "afforded the opportunity to become a full participant in our society" (p. 267), is tantamount to overruling Brown v. Board of Education. There exists an educational obligation to prepare all students to reach their fullest potential as salient members of society capable of meeting the demands of both the individual and the community. Brown and Adler [16] bolster this position in that "if populations are to thrive in the foreseeable future they will increasingly depend on the availability of robust local ecosystems of resources" (p. 17) that cherish creativity and innovation. This sentiment is directly related to the need for society to have authentic, creative, and innovative individuals who can both create and provide for the distribution of such resources.

Pinar [17] discusses how curriculum theory has become marginalized in the U.S. due to a continued anti-intellectualism agenda relegating teachers to mere technicians as opposed to masters of their craft. Further, educators have increasingly become a convenient target of an accountability system where the focus is on measurable outcomes as opposed to student learning. Pinar describes aspects of teaching that once embraced the intellectual freedoms of teacher preparation emphasizing "individuality...originality, creativity" (p. 183) used to enhance the learning process, have been compromised diminishing the anthem of academic freedom. Eisner [18] contends that educators must once again aspire to appreciate the nuance and subtly of education, whereby engaging in a form of "educational connoisseurship" (p.219).

Unfortunately, there is not a simple solution as Pinar [17] insists that policy decisions that have been relegated to the federal level, No Child Left Behind (NCLB) legislation, fail to address the needs of a diverse student population, thus failing to achieve its stated purpose and yet inconceivably remain in effect. Educators have been reduced to mere technicians, faithfully feeding the prescribed content to students who will then be tested on their objective knowledge of the material. Lankshear and Knobel [19] argue that this new emphasis occurred as a means of disrupting the vision of professionalism for teachers and Pinar would agree suggesting that this agenda is serving to further the anti-intellectualism educational shift by disenfranchising educators.

The educational system has thus been relegated to one of competition, where schools compete for funding based upon the outcomes of high stakes testing and fail to fully consider what, why, and how teaching is occurring [1]. Eisner [18] will insist that while the educational rhetoric remains focused on higher standards, the subversive truth is that it implies the need for high stakes measurement. Pinar [17] stresses that educators are being "forced to abandon their intellectual freedoms to choose what they teach, how they teach, and how they assess student learning" (p. 182). He insists that society has been deluded into believing "the commonsensical argument...[of] all that matters is the bottom line - scores on standardized tests" (p. 181), thus completing the educational shift in America to one based on a business model. It can then be argued that a system of national testing creates a de facto national curriculum.

According to Lankshear and Knobel [19], 21 ${ }^{\text {st }}$ century learners crave a more active voice in the educational process, as they aggressively seek ways to enrich their individual learning experience. We now live within an ever-increasing globalized community, where it behooves educators, K-16, to cultivate an atmosphere of collaboration that moves beyond the classroom and into a world where preexisting barriers no longer apply [9]. Cultivating local, national, and 
international partnerships connect with Barkely et al. [6] when they advocate for the need of professional learning communities to address barriers of student success. These newly established learning communities could be organized through $21^{\text {st }}$ century technologies combined with the individual autonomy to pursue them more fully. Kant, as cited by Buchner [5], is a champion of developing autonomy and discusses the aim of authentic education as a means for this development by the awakening of students to "ripe individual thinking" (p. 24). The $21^{\text {st }}$ century is the right time to yoke the authenticity advocated by Kant with modern technologies and establish a global connectedness between educational students, scholars, and communities.

These new approaches also foster individual selfauthorship as espoused by Raz [20] and entice a more globally responsive perspective that can lead to meaningful pedagogical practices. Arguably, these new technologies have transformed the way society functions placing education as the ultimate prize and leaving those unable to engage at a distinct disadvantage. The symbiotic relationship between technology integration and society is obvious, as one can no longer exist without the other. Truly, our modern society is both informed by and informs the advancement and use of technology. Lankshear and Knobel [19] advance the idea that "If we are to learn deeply, we need access to the means, contexts, and tasks" (p. 212) that are innate to the very creation of knowledge. It is Jonassen, Carr, and Yueh [21] who insist that educational technology provides that access by offering learners a near limitless potential in the form of "knowledge construction tools" (p. 24), which emphasize the capacity to organize, synthesize, and demonstrate learning.

Finally, it is through these $21^{\text {st }}$ century technologies that I will be afforded the opportunity to more fully develop local, national, and international partnerships that will in turn inform the praxis of our UWL teacher candidates. This speaks to the very heart of embracing $21^{\text {st }}$ century through a curricular lens. Kumaravadivelu [8] demonstrates the innate need to have educators, both current and future, possess the capacity to evolve and meet the challenge of teaching in a globalized world. It is in this new world where professionalism elevates the would-be teacher to embrace both content knowledge as well as the capacity to culturally respond to the needs of students of the global society.

\subsection{Partnerships, autonomy, technology}

Since the Age of Enlightenment, individuals have endeavored to understand her or his positionality in the world in which they live. The understanding of that reality is founded upon the experiences associated with held beliefs, values, and actions, as well as the motivations and freedoms behind those actions [5]. Such considerations can be evaluated by the conscious act of reflecting upon those experiences and then using that interpretation as a guide for choosing an action, as individuals create their own reality through choice. Viewing the educational process through a lens of collaboration, such as those outlined above, furthers this endeavor where the individual is encouraged to consider his or her place in an evolving world [12].

For those of us in the US, the freedom to choose is a deeply held individual conviction that can inadvertently hinder one's ability to view other educational perspectives or cultural identities appropriately. For example, working within small, self-assignment collaborative groups is commonplace throughout the American K-16 system of learning, and remains a growing phenomenon throughout the world of education. My students often view its absence as undesirable, as they question the lack of individual choice when studying systems of education where the needs of the individual are not as significant as are the needs of the collective. Such considerations are necessary for becoming a globally responsive educator who willfully, autonomously, seeks to wrestle with the social forces that influence teaching and learning.

The question concerning the importance or significance of a population consisting of autonomous citizens of a modern democracy, who exercise authentic and creative thinking, begs to be addressed. Perhaps the oldest view could be considered through the educational philosophies of Plato, who extolled the merits of the search for self-knowledge, the ability to reason, and the form of value. For Plato [22], the benefits of education serve the best interest of the individual as well as society, in that happiness is the result of self-realization. Happiness is interrelated to the ability to comprehend one's capacity to achieve his fullest potential. In this pursuit a connection clearly exists between the ideals of Bruner [3], Eisner [18], and Raz [20] to the theories of the ancients. Plato argues that the only way individuals can truly perceive the real world is not through their human senses, but rather, through an intellectual understanding. This is the foundation for Bruner's appreciation of the process of learning where the student possesses both the understanding and the capacity to manipulate that understanding. The modern democratic state demands citizens who not only understand that they hold a participatory role, but the appreciation that the chosen role can take shape as they see fit.

Plato [22] continues with the idea that a good society is one that emphasizes the intellectual development of its citizens and that a prosperous citizen, is one who serves the needs of the community 
knowing that education is a life-line. It is Kant [5] who advocates the "ideal worth and beauty of a free humanity" (p. 24) is based upon the awakening of individual thought. Is this not the base sentiment of a modern liberal democracy where self-fulfillment serves to enrich society and self-knowledge contributes to equality [20]? Thomas Aquinas advocates that freedom, to an ideal state, is a fundamental right and this liberty provides a means for each member to reach his or her fullest potential in conjunction with the potential of the state. Again, Kant [3] ascribes value to education by its very nature as a "positive constructive force in human character" (p. 28). The modern democracy, now more than ever, needs individuals willing to take these concepts to heart, and lead others in a time of increasing inequality, strife, and discord.

Raz [16] espoused the advantages of autonomy as a means for individuals to cope with evolving technologies and the fluidity associated with both "economic and social conditions" (p. 370) of the modern age. As future teachers, my UWL students must continue to move beyond simply becoming content experts and instead look to invigorate the autonomous self who is able to grow and develop based upon the economic and social needs of their students. In this regard, we can attach Bruner's [4] position in his appreciation of the idea involving selfauthorship. He ponders the purpose of education in terms of enabling "individual human beings to operate at their fullest potential" (p. 67), through the equipment of both skills and the understanding of how best to apply those skills.

In this sense, the pedagogical praxis of my students will be influenced by their collaborative experiences, which will further embolden them to reflect and exercise individual self-efficacy through selfreflection [7]. Fostering global partnerships, based upon the autonomous self to choose how and when to engage, will ultimately provide the flexibility of the individual to adapt and circumvent challenging situations that could otherwise preclude future students from active participation.

Advancing the understanding that we now live within a global community holds unique implications for future educators and calls us to assume a curricular lens of collaboration. These implications will guide our practice in preparing students to view the world through a globalized perspective [9] where previous barriers have been removed. In this modern age, it is now essential for individuals to learn to adapt to alternating situations as society has become enveloped with change, as we continue to experience the passing of the industrial society and the dawning of the knowledge and relational age. The transformation of the global economy has rapidly increased, revealing a need to prepare individuals who can successfully and collaboratively engage within an evolving society [8].

\section{Conclusion}

It is my position to advance a curricular frame of Personal Growth: Autonomy Doll [23] discusses the need for a new curricular frame, one "where curriculum becomes process, learning and understanding...through dialogue and reflection. Learning and understanding are made (not transmitted) as we dialogue with others and reflect on what we and they have said" (p.157). This is a unique aspect, and one that Bruner [4] would agree with wholeheartedly, as he affirms the idea that humans are unique in that they learn from one another. Doll further elaborates on his vision of a new frame with the understanding that the "learner...needs to know the material studied well enough...to solve, interpret, analyze" (p.164), but the learner also must be able to "play with the material in imaginative and quirky manners" (p.164) as well. How is it possible for individuals who are over tested and evaluated on subjective knowledge through high stakes testing going to possess the freedom to not only analyze material, but also play with it in a manner that encourages innovation? It is in this juncture where the curricular frame of personal growth and autonomy fit. This frame celebrates the idea that students will learn how to think, as opposed to simply being provided more information to remember [5]. The framework of personal growth and autonomy will embrace the educational approach "that unapologetically recognizes the artistry of teaching" (p.22).

Personal growth could be discussed in similar terms to the concept of self-actualization established by Eisner [18]. He considers it to be a holistic process of fostering fulfillment through authenticity and selfauthorship through the "integration of cognitive, creative, aesthetic, moral, and vocational dimensions of being human" (p.38). Remember this level of fulfillment is in line with the opinions offered by Raz [20] in that fulfillment is established through the exercise of self-direction throughout the course of ones' life. Likewise, the frame of personal growth and autonomy maintains an emphasis on the significance behind the process of learning how to learn [3]. This learner-centered approach is where the personal needs and desires of students are met and enriched to support the function of society. Joseph [7] emphasizes the need for substantial education reform, but it must embrace a student-centered approach that contributes to the development of $21^{\text {st }}$ Century skills for the learner, the instructor, and the administrator.

This curriculum framework or orientation, as discussed by Joseph [7], emphasizes that the 
educational process begins with the student at the center where the onus will remain on cultivating original, autonomous, and creative thinkers through interaction. Since the genesis of the information age of the 1990's, connecting with one another has become simplistic in nature opening the world to new exchanges of ideas, resources, and communication [16]. This new access will serve to satisfy our new desire for knowledge through dynamic interactive technologies, which have elevated the methods of the $21^{\text {st }}$ Century skills for collaboration and cooperation [19].

According to Schrage [24] the $21^{\text {st }}$ Century is more than an age of information, as we living in a "relationship revolution" (n.p.), where the connectivity that we enjoy with one another is to be utilized to enhance the learning community. Therefore, this frame is based upon one side of the constructionist position, which is constructionism, where learning is centered on the shared creation of meaning that is fashioned through the social context of a functioning society. This approach to meaning making is viewed from a collective epistemological perspective, as truth is socially defined based upon the context of the lived experience of those in the shared community. This process yokes the natural interests of the student and applies those to the learning process [18]. We must seek to move further in our view of curriculum and high impact practices, as we advance the need to utilize the theory of individual relevance where content is related to the visceral needs as well as the very lives of our learners.

Many scholars, including Kant [5] speak of autonomy as a theory and practice that can be adapted for educational endeavors. They advocate for the development of individuals who are capable of making independent life choices through self-regulation, reason, and reflection. These attributes are essential in this curriculum frame in the form of learner autonomy. This conception of autonomy incorporates the student driven concept of self-directed learning in a specific course of study, through the exercise of choice in topic, activity, and assessment [16]. The gains of utilizing this approach to curriculum and instruction, especially in relation to high impact practices, as a way to ensure a holistic advancement of the learner with a high capacity for becoming selfactualizing and authentic contributors.

Brown and Adler [16] as well as Lankshear and Knobel [19] demonstrate the cognitive aspect of utilizing a pedagogical approach that supports selfregulation through the exercise of self-directed learning activities. In this process, students evolve from the passive position of simply receiving information, to an active role of creating knowledge. Any learning approach that incorporates these process driven aspects serves to celebrate the creative, authentic self-authorship, which leads to individual discovery.

From a very practical sense, this curriculum frame, promotes the need for students to appreciate the values of individuality so that they can support the foundations of our society. This construct exists as a means of living collectively toward the common social goals of political government, social welfare, economic considerations, and educational activities. Morse [15] reinforces this function of education as noted by the ruling of Brown v. Board of Education where schools serve to facilitate "cultural assimilation, preparation for participation in the political process, and training for economic" (p.266) opportunities. Through this educational process, individuals agree to live together in harmony under the protection of expressed laws. These communities form the basis of society through expressed norms, ideals, and beliefs.

This educational framework provides for the encouragement of active participation where students assist in the development of the curriculum. Students in cooperation with the instructor negotiate responsibilities, assessment, and learning objectives based upon the collective sense of competencies and curiosities. The emphasis of instruction is based upon interaction with the integration of each participant's feelings, attitudes, and interpretations. According to Eisner [18] the relevance aspect encompasses teachers developing "educational programs in concert with students" rather than following the current prescriptive curriculum now gripping the nation (p.69). This approach emphasizes the social component as both student and teacher are morphed into "living creatures attempting to broaden and deepen the quality of their experience" (p. 70).

Consider personal relevance unfolding as students and teachers collaboratively identify areas of personal interest and then have those notions incorporated into the unit planning. For example, when attempting to teach first year college students how to engage in scholarly writing, and the class indicates a strong connection to the topic of "going green". As the instructor with a curriculum focused on personal growth, the negotiated writing prompt could potentially include such topics as energy, environment, and personal consumption. The significance is found by connecting abstract concepts to concrete ideas inherent to the lives of each student. Eisner [18] would insist that this approach to curriculum would avoid the "meaningless routines" (p.69) associated with the traditional curriculum.

This form of curriculum promotes educational autonomy through a democratically driven process that provides a noticeable sense of transference of the learning into a larger social role vis-a-vis participation 
in the American Democracy. The benefit of aligning the curriculum to the needs and interests of the student where the peculiarity of each individual can be fostered in a supportive learning environment, is powerful. Through the curriculum orientation of personal growth and autonomy students achieve personal fulfillment as they discover and develop unique identities through meaningful academic experience [18], which is learner-centered [9] and process driven [4]. That sounds a great deal like the necessary fundamentals of autonomy as discussed earlier by Kant [5] and Raz [20].

Raz [20] contends that self-direction and the ability to exercise "authorship" (p. 370) over one's life is an indispensable aspect to the sense of individual wellbeing. I contend that future educators, who exercise a similar level of self-direction, will likewise experience a comparable sense of professional well-being. It is my position that students who engage in collaborations, whether it be local, national, or international, are placed upon a path of individual discovery. This occurs as learners constantly compare ideas and ideologies through internal and external exploration. If those of us within academia possess the ability to offer education majors the chance to participate in local, national, and global collaborations or partnerships, the result will be a self-directed increase in cultural literacies and pedagogical innovation.

I was able to witness this transformation in my students who lived and learned in China. What began as a Western epistemological approach to teaching and learning held by my Midwestern UWL undergraduates, soon morphed into a view of curriculum that embraced human differences. Initially, students underestimated the teaching practices of our Chinese counterparts until they were afforded the opportunity to teach content as guest instructors. UWL students found themselves immersed within new cultural context(s) through the inclusion of Chinese students, educators, and community partnerships. Through planned excursions to iconic pleases such as The Great Wall, The Forbidden City, and the Terracotta Army our students encountered authentic first hand experiences with histories, philosophies, and cultural perspectives that challenged previously held conceptions. The result of this intensely and purposely designed study abroad program was to significantly increase the cultural literacies of our UWL education majors, as we collaboratively wrestled with global pedagogical approaches, social determinants of human development, and the very real sense of "otherness".

If it is possible for the autonomous person to lead a more robust life, as offered by Buchner [5], then I believe that the same holds true for future educators.
By inviting domestic teacher candidates to view the world through a curricular lens of collaboration, and then provide the framework through which to engage on meaningful, real-world projects, I have witnessed our students as they become intrinsically motivated to drive the learning endeavor. In this, I have assumed a curricular lens of collaboration where students have the opportunity to develop and participate in sustainable local, national, and international educational partnerships. Additionally, these collaborations serve to sharpen pedagogical practices to bolster effective teaching strategies.

I view this line of thinking as a means of pursuing meaningful and actionable $21^{\text {st }}$ century collaboration projects that yoke the essential need for future educators to view teaching and learning from a global perspective. As educators, we must foster the capacity within our students to reach beyond traditional modes of teaching through intentionally seeking and developing lasting partnerships from local, national, and international communities that provide greater meaning for our students.

All primary learning objectives associated with the UWL travel abroad program to China incorporated the concept that pursing a deeper understanding of education and human development within a globalized society requires immersion within a community beyond that of the Westernized world.

By the end of the study aboard program, students were able to:

- Evaluate the benefits and consequences of globalization

- Analyze and articulate the social determinants of education and human development from a global perspective

- Design and Create multimodal projects that capture the essence of epistemological and pedagogical approaches for diverse global communities

- Evaluate and Analyze diverse perspectives of developmental issues from within a global perspective

- Apply, Analyze, and Evaluate norms, traditions, and structures of schooling from within a $21 \mathrm{st}$ century global society

- Create effective communication connections between concepts and content via writing (APA)

- Analyze current social, political, and development between China and the U.S.

Through my recent participation at the London International Conference on Education (LICE), I was presented with the multiple opportunities to share my ideas, invite critical friends to offer feedback, and identify potential future partnerships from across the globe. Cultivating globally responsive educators is a global responsibility in itself, and one that requires a 
pedagogical approach that supports sustainable partnerships. We must resist the ubiquitous compartmentalization and sedentary thinking that pervades our individual systems of education. Instead, let us collaboratively foster the authenticity and creativity of students within teacher preparation programs to embark upon the exploration of the field of education through a curricular lens with a focus on collaborating within the global community. Let us form partnerships where students from across the world embrace global professional learning communities as they lead our singular community to a brighter educational future.

This understanding is significant in light of this ongoing work, which seeks to better understand the benefits of working collaboratively with students and scholars from a perspective that values the benefits and consequences of globalization. Future educators must be equipped to engage the world in which they live, whether through technologies or not, and possess the freedom and self-direction to drive the collaborative learning experience.

\section{References}

[1] Fink, L. D. (2013). Creating significant learning experiences. Revised and updated: An integrated approach to designing college courses. San Francisco, CA: JosseyBass.

[2] Wenger, E. (1998). Communities of practice: Learning, meaning and identity. Cambridge, England: Cambridge University.

[3] Bruner, J. S. (1971). "The process of education" revisited. The Phi Delta Kappan, 53(1), 18-21. Retrieved from www.jstor.org/stable/20373062 (Access Date: 16 February, 2017).

[4] Bruner, J. S. (1996). The culture of education. Cambridge, MA: Harvard University.

[5] Buchner, E. F. (1904). The educational theory of Immanuel Kant. Philadelphia, PA: J. B. Lippincott Company.

[6] Barkely, E.F., Cross, K.P. \& Howell Major, C. (2005). Collaborative learning techniques: A handbook for college faculty. San Francisco: Jossey-Bass

[7] Joseph, P. B. (2011). Conceptualizing curriculum. In P. B. Joseph (Ed.), Cultures of curriculum (2nd edition). New York, NY: Rouledge.

[8] Kumaravadivelu, B. (2012). Rethinking global perspectives and local initiatives in language teaching. In S. B. Said \& L. J. Zhang (Eds.) Language teachers and teaching: Global perspectives, local initiatives. New York, NY: Routledge.
[9] Zhao, Y. (2012). World class learners educating creative and entrepreneurial students. Thousand Oaks, CA: Corwin.

[10] Welner, K. G., \& Carter, P. L. (2013). Achievement gaps arise from opportunity gaps. In P. Carter \& K. Welner (Eds.), Closing the achievement opportunity gap: What America must do to give every child an even chance (pp. 110). New York, NY: Oxford University.

[11] DuFour, R., Eaker, R., \& Karhanek, G. (2004). Whatever it takes: How professional learning communities respond when kids don't learn. Bloomington, IN: National Educational Service.

[12] Ang, S., \& Van Dyne, L. (Eds.) (2008). Handbook on Cultural Intelligence: Theory, Measurement and Applications. Armonk, NY: M.E. Sharpe.

[13] U.S. Department of Education, National Center for Education Statistics. (2013). The Condition of Education 2013 (NCES 2013-037), Institutional Retention and Graduate Rates for Undergraduate Students. Retrieved from http://nces.ed.gov/pubs2013/2013037.pdf. (Access Date: 26 January, 2017).

[14] Kuh, G. D. (2008). "High-impact educational practices: What they are, who has access to them, and why they matter." AAC\&U, Washington, D.C.

[15] Morse, T. E. (2004). Ensuring equality of educational opportunity in the digital age. Education and Urban Society, 36(3), 266-279. doi:10,1177/0013124504264103.

[16] Brown, J. S., \& Adler, R. (2008). Minds on fire: Open education, the long tail and learning 2.0. Educause Review, 43(1), 16-32. Retrieved from: https://net.educause.edu/ir/ library/pdf/ERM0811.pdf. (Access Date: 15 November, 2016).

[17] Pinar, W. F. (2012). What is curriculum theory? (2nd edition). New York, NY: Routledge.

[18] Eisner, E. W. (1985). The educational imagination. New York, NY: MacMillan.

[19] Lankshear, C., \& Knobel, M. (2011). New literacies: Everyday practices and social learning. New York, NY: McGraw-Hill.

[20] Raz, J. (1986). The morality of freedom. Oxford, England: Clarendon.

[21] Jonassen, D. H., Carr, C., \& Yueh, H. (1998). Computers as mindtools for engaging learners in critical thinking. Techtrends, 43(2), 24-32. October 31, 2016, doi:10.1007/BF02818172.

[22] Plato. (trans. 1935). The republic of Plato. F. MacDonald-Cornford (Trans.). Cambridge, MA: Harvard University. 
International Journal for Cross-Disciplinary Subjects in Education (IJCDSE), Volume 8, Issue 4, December 2017

[23] Doll, W. E. (1993). A post-modern perspective on curriculum. New York, NY: Columbia University.

[24] Schrage, M. (2001). The relationship revolution. Technology and Society: Merrill Lynch Forum. Retrieved from http://yitan.com/The_Relationship_Revolution.

(Access Date: 21 September, 2016). 